\title{
Histomorphological Spectrum of Lesions in Nephrectomy Specimen
}

\author{
Dipika Basnet, ${ }^{1}$ Ramesh Makaju, ${ }^{1}$ Rachana Dhakal, ${ }^{1}$ Binita Lama, ${ }^{1}$ Nikita Gautam ${ }^{1}$ \\ 'Department of Pathology, Dhulikhel Hospital, Kathmandu University Hospital
}

\begin{abstract}
\section{Introduction}

Nephrectomy is a common and standard surgical practice in urology. It has pivotal role in diagnosis, treatment and prognosis of disease. It is indicated in patients with irreversible kidney damage following chronic infection, trauma, obstruction and malformation as well as renal malignancy. The objective of this study was to analyze the histomorphological spectrum of various lesions in nephrectomy specimens with special emphasis on grading and staging of renal carcinoma.
\end{abstract}

\section{Methods}

This is a retrospective study done from January 2015 to December 2020 in the Department of Pathology, Dhulikhel Hospital - Kathmandu University Hospital (DH - KUH). Relevant clinical data of the patients were obtained from the histopathological records of the patient from the pathology department.

\section{Results}

A total of 70 cases were studied, out of which 60 were simple nephrectomy specimens, followed by 8 radical and 2 partial nephrectomy specimens. The age of patient ranged from 2 to 74 years. Highest percentage of nephrectomy was seen in $4^{\text {th }}$ decade of life. Male population comprised $54.28 \%$ of nephrectomy. Non-neoplastic lesions constituted 53 cases and chronic pyelonephritis was the most common lesion. Out of 17 neoplastic lesions, $76.47 \%$ of cases were malignant. Clear cell renal cell carcinoma was the most common malignant tumour.

\section{Conclusions}

This study gives a fair insight into the incidence of neoplastic and non-neoplastic lesions of kidney requiring nephrectomy in this institution.

Keywords: chronic pyelonephritis; clear cell renal cell carcinoma; nephrectomy

Correspondence: Dr. Dipika Basnet, Department of Pathology, Dhulikhel Hospital, Kathmandu University Hospital. Email: dipikabasnet1@gmail.com, Phone:+977-9841608681. 


\section{INTRODUCTION}

The kidneys are vital organs of the body. They are involved in various pathological processes including neoplastic and non-neoplastic disease which are collectively responsible for great deal of morbidity and mortality throughout the world. ${ }^{1}$ Chronic pyelonephritis is one of the commonest non-neoplastic disease of kidney. However, cancer of the kidney amounts to $2 \%$ of the total human cancer burden, with approximately 190,000 new cases diagnosed each year. ${ }^{2}$

Nephrectomy is one of the modalities of treatment that provides relief to patients from various chronic and life threatening diseases and in some cases makes way for renal transplant. ${ }^{3}$ There are three types of nephrectomy which are performed for different indications which includes simple, partial and radical. Simple nephrectomy is indicated in patients with an irreversibly damaged kidney due to symptomatic chronic infection, obstruction, calculus disease or severe traumatic injury. ${ }^{4}$ Radical nephrectomy is the gold standard treatment for localized renal carcinoma with a normal contralateral kidney. However, partial nephrectomy is preferred to completely remove the primary tumor while preserving the largest possible amount of healthy renal parenchyma. ${ }^{5}$

Histomorphological examination is not only required for the exact diagnosis of lesions but is essential to establish histologic type. Besides, it provides histopathological prognostic markers like tumor size, histological subtype, nuclear grade and stage in cases of malignant lesions. ${ }^{6}$

The aim of this study was to evaluate the neoplastic and non-neoplastic conditions among nephrectomy specimens, identify the frequency of histopathological features among nephrectomy specimens in correlation with age and sex and emphasize on grading and staging of the renal carcinomas.

\section{METHODS}

This retrospective study was carried out in the Department of Pathology, Dhulikhel Hospital - Kathmandu University Hospital (DH-KUH). Ethical approval from the Institutional Review Committee was obtained (Approval number: 11/2021). 70 nephrectomy specimens received in the department of pathology during a period of five years from January 2015 to December 2019 were included in the study. All the nephrectomy biopsies including simple, radical and partial nephrectomy specimens were reviewed. Core needle biopsies from renal masses were excluded.

Relevant clinical data which consisted of information regarding age, sex, clinical diagnosis, laterality of the specimen, gross findings, like size of the tumor were obtained from the histopathological records. All specimens were fixed in $10 \%$ formalin, then processed into paraffin embedded sections and stained with Hematoxylin and Eosin. These Hematoxylin and Eosin stained slides were retrieved for microscopic examination. Frequency of various neoplastic and non-neoplastic lesions was listed. Malignant tumors -Renal Cell Carcinomas (RCC) were graded using Fuhrman nuclear grade system. ${ }^{7}$ Patient's data was entered in Microsoft Excel and descriptive data analysis was done using Statistical Package for Socical Sciences(SPSS) 16.0 software. Results were expressed as frequency and percentage.

\section{RESULTS}

A total of 70 cases of unilateral nephrectomy specimens were studied. Out of these, $60(85.7 \%)$ were simple nephrectomy followed by $8(11.4 \%)$ radical nephrectomy and $2(2.9 \%)$ partial nephrectomy specimens. Neoplastic lesion were $17(24.29 \%)$ and non-neoplastic lesions were $53(75.71 \%)$ in number. 
Table 1. Distribution of neoplastic and non-neoplastic lesion by age and sex. $(n=70)$

\begin{tabular}{|l|c|c|c|c|c|c|}
\hline \multirow{2}{*}{ Age (years) } & \multicolumn{2}{|c|}{ Benign and Malignant lesions } & \multicolumn{2}{|c|}{ Non-neoplastic lesions } & \multirow{2}{*}{ Total (n) } & \multirow{2}{*}{ Percentage (\%) } \\
\cline { 2 - 5 } & Male (n) & Female (n) & Male (n) & Female (n) & & 4 \\
\hline $0-10$ & 1 & 1 & 1 & - & 3 & 4.29 \\
\hline $11-20$ & - & - & 2 & 2 & 4 & 5.71 \\
\hline $21-30$ & 2 & - & 4 & 11 & 17 & 24.29 \\
\hline $31-40$ & 2 & 1 & 4 & 3 & 10 & 14.29 \\
\hline $41-50$ & 4 & 2 & 7 & 5 & 18 & 25.71 \\
\hline $51-60$ & 1 & - & 7 & 3 & 11 & 15.71 \\
\hline $61-70$ & 1 & 1 & 1 & 3 & 6 & 8.57 \\
\hline$>70$ & 1 & - & - & - & 1 & 1.43 \\
\hline Total & 12 & 5 & 26 & 27 & 70 & 100 \\
\hline
\end{tabular}

Highest percentage of age undergoing nephrectomy was between 41-50 years age group with $18(25.71 \%)$ cases (Table 1$)$. Also nephrectomies for neoplastic lesions were highest in the same age group consisting of $4(35.29 \%)$ cases. Least affected age group that underwent nephrectomy was $1^{\text {st }}$ decade with only $3(4.29 \%)$ cases. The youngest patient was 2 years old and the oldest was 74 years old.

Out of the total nephrectomies, 38 (52.29\%) cases were from right side and 32(45.71\%) cases from left.

The number of male and female patients were 38 (54.28\%) and 32(45.72\%) respectively. Neoplastic as well as malignant lesions were more common in male compared to female (Table 2).

Table 2. Sex wise distribution of lesions in nephrectomy specimen. $(n=70)$

\begin{tabular}{|c|c|c|c|}
\hline Lesions & Male (n) & Female (n) & Total \\
\hline Neoplastic & 12 & 5 & 17 \\
\hline Benign & 4 & - & 4 \\
\hline Angiolipoma & 3 & - & 3 \\
\hline Papillary adenoma & 1 & - & 1 \\
\hline Malignant & 8 & 5 & 13 \\
\hline Clear Cell RCC & 3 & 4 & 7 \\
\hline Papillary renal cell carcinoma Type 2 & 1 & - & 1 \\
\hline Chromophobe RCC & 1 & - & 1 \\
\hline Squamous Cell Carcinoma & 1 & - & 1 \\
\hline Wilms' Tumor & 1 & 1 & 2 \\
\hline Small cell Neuroendocrine carcinoma & 1 & - & 1 \\
\hline Non-neoplastic & 26 & 27 & 53 \\
\hline Chronic pyelonephritis & 24 & 24 & 48 \\
\hline Acute on chronic pyelonephritis & - & 1 & 1 \\
\hline Simple cyst & - & 1 & 1 \\
\hline Renal tuberculosis & 1 & 1 & 2 \\
\hline Xanthogranulomatous Pyelonephritis & 1 & - & 1 \\
\hline Total & 38 & 32 & 70 \\
\hline
\end{tabular}


Non-neoplastic lesions constituted 53 (75.71\%) cases and chronic pyelonephritis was the most common finding with equal distribution among both the sexes. Other non-neoplastic findings included $1(1.88 \%)$ case of acute on chronic pyelonephritis, $1(1.88 \%)$ case of chronic pyelonephritis with simple cyst, 1(1.88\%) case of xanthogranulomatous pyelonephritis and $2(3.76 \%)$ cases of renal tuberculosis. Out of the diagnosed neoplastic lesions 13 $(76.47 \%)$ cases were malignant. The clear cell renal cell carcinoma was the most common malignant neoplasm consisting of 7 (53.85\%) cases. Other malignant neoplasms included 2 (15.38\%) cases Wilms' tumour, 1 (7.69\%) case of papillary renal cell carcinoma Type 2, 1(7.69\%) case of chromophobe RCC, $1(7.69 \%)$ case of squamous cell carcinoma and $1(7.69 \%)$ case of metastatic small cell neuroendocrine tumor. Among the benign lesions angiolipoma was the most common lesion consisting of $3(75 \%)$ cases (Table 2).

Table 3. Age wise distribution of lesions in nephrectomy specimens. $(n=70)$

\begin{tabular}{|l|l|l|l|l|l|l|l|l|}
\hline Lesions & $0-10$ & $11-20$ & $21-30$ & $31-40$ & $41-50$ & $51-60$ & $61-70$ & $>70$ \\
\hline Angiolipoma & - & - & 1 & - & 1 & - & - & 1 \\
\hline Papillary adenoma & - & - & 1 & - & - & - & - & - \\
\hline Clear cell RCC & - & - & - & 1 & 4 & - & 2 & - \\
\hline Papillary RCC Type2 & - & - & - & - & 1 & - & - & - \\
\hline Chromophobe RCC & - & - & - & 1 & - & - & - & - \\
\hline Squamous cell carcinoma & - & - & - & 1 & - & - & - & - \\
\hline Wilms' tumor & 2 & - & - & - & - & - & - & - \\
\hline Small cell NEC & - & - & - & - & - & 1 & - & - \\
\hline Chronic pyelonephritis & 1 & 3 & 13 & 7 & 10 & 10 & 4 & - \\
\hline Acute on chronic pyelonephritis & - & - & - & - & 1 & - & - & - \\
\hline Chronic pyelonephritis with simple cyst & - & - & - & - & 1 & - & - & - \\
\hline Renal tuberculosis & - & - & 2 & - & - & - & - & - \\
\hline Xanthogranulomatous pyelonephritis & - & 1 & - & - & - & - & - & - \\
\hline
\end{tabular}

RCC: Renal Cell Carcinoma; NEC: In children less than 10 years, Wilms' tumour was

\section{Neuroendocrine carcinoma}

The histological distribution of the lesions showed that chronic pyelonephritis, the most common lesion was common in age group of 2130 years and renal cell carcinoma in $41-50$ years age group (Table 3 ). the most common lesion diagnosed (Table 3).

Out of 7 cases of renal cell carcinoma maximum diameter of primary tumour was $9 \mathrm{~cm}$ and least was $1.5 \mathrm{~cm}$. Fuhrman nuclear grading was done in the malignant tumours where nuclear grade 
II was the most common grade, seen in 5 cases (71.44\%) (Table 4).

Table 4. Histomorphological features of Clear cell Renal cell carcinoma. $(n=7)$

\begin{tabular}{|l|l|l|}
\hline $\begin{array}{c}\text { Histomorphological } \\
\text { features }\end{array}$ & $\begin{array}{c}\text { No of cases } \\
(\mathbf{n})\end{array}$ & $\begin{array}{c}\text { Percentage } \\
(\%)\end{array}$ \\
\hline Staging & 5 & 71.44 \\
\hline PT1 & 1 & 14.28 \\
\hline PT2 & 1 & 14.28 \\
\hline PT3 & - & - \\
\hline PT4 & & \\
\hline Nuclear grade & 2 & 28.56 \\
\hline Grade I & 5 & 71.44 \\
\hline Grade II & - & - \\
\hline Grade III & - & - \\
\hline Grade IV & & \\
\hline
\end{tabular}

\section{DISCUSSION}

Renal diseases are responsible for a great deal of morbidity as well as mortality. Many pathological processes including neoplastic and non-neoplastic disease involve the kidney. Severe cases of chronic renal disease like chronic infection, trauma, obstruction and malformation as well as renal malignancy destroy the renal parenchyma of both the kidneys resulting in chronic renal failure. ${ }^{3}$ The treatment of choice for patient in end stage renal disease and neoplastic lesion is nephrectomy. The indication and type of nephrectomy depends on various factors like type of lesion: extent of damage, general condition of the patient and status of the contralateral kidney. ${ }^{8}$

In this study, a total of 70 cases of unilateral nephrectomy specimens were analyzed. Out of these, 60(85.7\%) were simple nephrectomy specimens. Eight radical nephrectomies were done for malignant tumors which constituted $11.43 \%$ in this study, in comparison to $7.1 \%$ and $22 \%$ in studies conducted by Amin et al and Fadil et al respectively. ${ }^{9,10}$ Out of 2 cases of partial nephrectomy, one was Wilms' tumor which was carried out to preserve the healthy renal parenchyma, in patient with bilateral tumour. Other case was done for cyst removal which histologically turned out to be clear cell renal cell carcinoma.

In the present study the age group of patients ranged from 2 years to 74 years. Majority of the patients belonged to age group of 41-50years which is similar to the study conducted by Suryawanshi et al, Bajaj et al and Vinay et al. $8,11,12$ In our study, male patients were $38(54.28 \%)$. Similarly male preponderance was seen in studies by Suryawanshi et al, Amin et al, Bajaj et al and Vinay et al. ${ }^{8,9,11,12}$ Right sided nephrectomy were more in number compared to left consisting of $38(58.29 \%)$ cases which was similar to studies conducted by Bajaj et al and Kumar et al. ${ }^{11,13}$ In contrast, left sided nephrectomy was more common in the study done by Fadil et al. ${ }^{10}$

Among the non-neoplastic lesions, chronic pyelonephritis, acute kidney injury, nephritic and nephrotic syndromes, renal cyst, chronic kidney disease, urinary tract obstruction are common. ${ }^{1}$ In this study, non-neoplastic lesions constituted a total of $53(75.71 \%$ ) cases which is concordant with the studies done by Suryawanshi et al and Kumar et al in which $24(72.73 \%)$ and $36(72 \%)$ cases of non-neoplastic lesions were present. ${ }^{8,13}$

Pyelonephritis is the inflammation involving the tubules, interstitum and renal pelvis. It is the most common disease of kidney which is caused by bacterial infection mostly secondary to ascending infection from the lower urinary tract due to urinary tract obstruction and stasis, vesicoureteral reflux and intrarenal reflux. ${ }^{1}$ It peaks with different age groups -infancy and early childhood, women of child bearing age and both men and women older than 60 years 
of age. ${ }^{11}$ In our study chronic pyelonephritis was the most common non-neoplastic lesion which is similar to findings of Suryawanshi et al and Bajaj et al. ${ }^{8,11}$ Majortiy of these patients were in the age group of 21-30 years followed by 41-50, 51-60 and 31- 40 years in our study. Likewise, chronic pyelonephritis was common in 21- 40, 41-50 years age group and $3^{\text {rd }}$ and $4^{\text {th }}$ decade of life in study conducted by Suryawanshi et al, Amin et al and Kumar et al respectively. ${ }^{8,9,13}$

Among the other non-neoplastic lesion 2(3.77\%) cases of renal tuberculosis were found which was comparatively less than Amin et al, Vinay et al and Kumar et al.,12,13 However, no case of renal tuberculosis were present in studies done by Suryawanshi et al and Bajaj et al. ${ }^{8,11}$ Xanthogranulomatous pyelonephritis comprised $1(1.89 \%)$ case which is similar to findings of Amin et al. ${ }^{9}$ Other studies showed higher frequency of Xanthogranulomatous pyelonephritis. ${ }^{11-13}$ Simple cyst consisted of $1(1.89 \%)$ case which is comparable to Bajaj et al and Kumar et al. ${ }^{11,13}$ However, some studies had no case of simple cyst. $8,11,12$ The discrepancies in the distribution of lesions among these studies are due to differences in the size of the sample, duration and place of study.

Both benign and malignant neoplasms can occur in the kidney. Malignant neoplasms are more common than benign and have diagnostic, therapeutic and prognostic implications. Renal cell carcinoma, the most common adult cell tumour is found to be two times more common in males. Wilms' tumour is the most common tumor in children. ${ }^{1}$ In present study, neoplastic lesions constituted $17(24.29 \%)$ cases which is similar to Suryawanshi et al and Kumar et al in which $9(27.27 \%)$ and $14(28 \%)$ cases of neoplastic lesions were present. ${ }^{8,13}$ Among the neoplastic lesions, $13(76.47 \%)$ cases were malignant which is in concordance with the study done by Suryawanshi et al, Amin et al, Bajaj et al, Vinay et al and Kumar et al. 8, 9,11-13

In our study maximum number of neoplastic as well as malignant cases were seen in males which is similar to Gupta et al, Suryawanshi et al and Amin et al. ${ }^{3,8,9}$

In the present study, clear cell renal cell carcinoma was the most common malignant neoplasm in adult and Wilms' tumour in children. All the cases of renal cell carcinoma were clinically diagnosed as malignant renal mass. However, one of nephrectomy done for cyst removal was clinically not suspected to be neoplastic lesion, which histologically turned out to be clear cell renal cell carcinoma.

Similar higher incidence of clear cell RCC was reported in studies done by Gupta $S$ et al, Suryawanshi et al, Amin et al, Shah et al, Aiman et al and Meena et al. 3,8,9,14-16 Wilms' tumour formed the most common malignant pediatric tumor in studies by Amin et al, Bajaj et al, Shah et al and Aiman et al. 9,11,14,15

Other malignant neoplasm included 1(7.69\%) case each of papillary renal cell carcinoma type 2 , chromophobe renal cell carcinoma, squamous cell carcinoma and metastatic small cell neuroendocrine tumor. Maximum number of renal cell carcinoma was in the age group of 4150 years which is similar to the findings of Bajaj et al and Meena et al. ${ }^{11,16}$ In the study conducted by Gupta et al, Amin et al and Aiman et al 51 - 70 years, $8^{\text {th }}$ decade and $61-70$ years was the age group to which highest percentage of renal cell carcinoma fell in. ${ }^{3,9,15}$ The difference in the variation in age group is likely due to the small number of malignant cases under study.

Among the 7 cases of clear cell renal cell carcinoma, maximum diameter of primary tumor was $9 \mathrm{~cm}$ and least was $1.5 \mathrm{~cm}$. Accordingly maximum number of cases were within pT1 consisting of $5(71.44 \%)$ cases with $1(14.28 \%)$ case each in pT2 and pT3. Similar to our study 
by Shah et al, maximum number of cases of clear cell renal cell carcinoma were in pT1 (37.5\%) with equal number of cases in pT2 and pT3 (2 cases) and single case in pT4. ${ }^{14}$

Following Fuhrman's nuclear grading in malignant tumors, nuclear grade II was the most common presentation comprising of 5(71.44 $\%)$ cases and remaining cases showed nuclear grade I. Similar majority of nuclear grade II clear renal cell carcinoma were observed by Gupta et al, Suryawanshi et al, Bajaj et al, Shah et al and Aiman et al. $3,8,11,14,15$

\section{CONCLUSIONS}

The present study provides a fair understanding of the histomorphological patterns of lesions in nephrectomy specimens in our institution which correlates with different other studies conducted in Southeast Asian region. Most common affected age group was 41- 50 years and the most common indication for nephrectomy was chronic pyelonephritis. Clear cell carcinoma was the most common adult malignancy while pediatric malignancy was Wilms'tumour.

\section{REFERENCES}

1. Kumar V, Abbas AK, Aster JC. Robbins and Cotran pathologic basis of disease. 9th ed. Philadelphia: Elsevier; 2015.

2. WHO. WHO classification of tumors of the urinary system and mal genital organs. 4th ed. France: IARC; 2016.

3. Gupta S, Sankhala K, Sanwalka M, Khatri J, Kumar D. A histomorphological study of nephrectomy specimnes in Rural rajasthan-A population based study. Journal of evolution of medical and dental sciences.2020; 9(31):2181-2186. https://doi.org/ 10.14260/jemds/2020/475

4. Pawar V, Mane V. Pathological spectrum of lesions in nephrectomy specimens in a tertiary hospital. Journal of evolution of medical and dental sciences.2015; 4(89):15479-15485.

5. Williams NS, O'Connell PR, McCaskie AW. Bailey and Love's short practice of surgery.27th ed. London: CRC Press;2018.

6. Algaba F, Trias I, Scarpelli M, BocconGibod L, Kirkali Z, Poppel HV.et al
Handling and pathology reporting of renal tumor specimens. Eur Urol. 2004;45:437-443.

7. Ackerman JR, Juan R. Rosai and Ackerman surgical pathology. 10th ed: Mobsy Elsevier; 2011.

8. Suryawanshi KH, Damle RP, Dravid NV, Rawandale AP, Surana A . Hisomorphological Analysis of lesions in nephrectomy Specimens: A 4 years study in a rural Hospital In india-our experience. Annals of Pathology and Laboratory medicine.2017;4(3):230-235, https://doi.org/10.21276/apalm.1111

9. Amin AN, Pai P, Upadhyaya K. A histopathological spectrum of Neohrectomy specimens in a tertiary hospital in southern. International Journal of Biological \& Medical Research. 2015;6(3):5173-5178

10. EI Fadil MA, Shafiq RM, Ahmed LI, Abdul WAG, Ahmed MG. Nephrectomy in adults: Asie Hospital experience. Saudi J kidney Dis transplant 1997; 8:423-7 
11. Bajaj H, Hathila R. Study of histomorphological spectrum of lesions in nephrectomy specimen in a tertiary care hospital in South Gujrat. International Journal of research in medical sciences.20202 may; 8(5):17061712 hhtp://dx.doi.org/10.18203/23206012.ijrms20201914

12. Vinay KS, Sujatha S. Histopathological Spectrum of Nephrectomy Specimens: Single Center Experience. Biomed J Sci\&Tech Res. 2018; 6(3): 52695273. https:/doi.org/ 10.26717/ bjstr.2018.06.001350.

13. Kumar MR, Meghana P, Vasudev V and Bharathi M. Histopathological Spectum of Nephrectomy Specimens. Annals of Pathology and Laboratory medicine. 2019; 6(1): 49-53. https://doi. org/ 10.21276/aplam.2280
14. ShahN, Goyal S. Histopathological study of nephrectomy specimens in a tertiary care hospital. Journal of Diagnostic Pathology and Oncology.2019; 4(1):3944 https://doi.org/ 10.18231/25813706.2019.0007

15. Aiman A, Singh K, Yasir M. Histopathological spectrum of lesions in nephrectomy specimens: A five year experience in a tertiary care hospital. Journal of the Scientific Society. 2013; 40(3): 148-154. https://doi.org/ 10.4103/0974-5009.120058

16. Meena SP, Pathak V, Shuheeja D, Bhati $\mathrm{R}$ and Riyaz S. Histomorphological profile of nephrectomy specimens in a tertiary care center of Rajasthan: A case series of 100 specimens. Internationa; Journal of current Research. 2017;9(2):47187-47190

Citation: Basnet D, Makaju R, Dhakal R, Lama B, Gautam N. Histomorphological Spectrum of Lesions in Nephrectomy Specimen. JCMS Nepal. 2021; 17(2); 93-100. 